\title{
The effects of prolonged handling, scopolamine, and physostigmine on the activity of isolated and socially reared rats
}

\author{
BARBARA J. MORLEY \\ Neurosciences Program, University of Alabama Medical School, Birmingham, Alabama 35294 \\ and \\ ELIZABETH WORSHAM \\ Center of Alcohol Studies, Rutgers University, New Brunswick, New Jersey 08903
}

\begin{abstract}
Sprague-Dawley albino rats were reared in one of three social environments: isolation, low density, or high density. Baseline activity, measured by photobeam crossings in a 15-min session, was assessed for 16 consecutive days. The response to 1 and $10 \mathrm{mg} / \mathrm{kg}$ of scopolamine and .05 and $.1 \mathrm{mg} / \mathrm{kg}$ of physostigmine was then assessed. It was found that isolated animals were more active than socially reared animals, and that this isolation-induced increased activity was not eliminated with repeated handling and behavioral testing. The activity of the animals in a low-density of group was not significantly greater than that of animals raised in a highdensity group. Scopolamine and physostigmine were both found to decrease activity, but there was not a differential effect of the drugs on animals raised in the three social environments. It was concluded that tactile stimulation does not alter the effects of isolation-rearing and that a baseline activity level can be established for the investigation of the physiological bases of the behavioral effects of isolation-rearing.
\end{abstract}

Recently, much attention has been given to the behavioral and physiological differences between animals raised in isolation and animals raised in various kinds of socially or perceptually enriched conditions. Since the young rat normally engages in a very high level of social activity, it is not surprising that social and/or environmental impoverishment can have pronounced effects upon adult behavior. For example, isolated animals differ from communally raised or socially enriched animals in that isolated animals are commonly found to be more active (e.g., Levitsky \& Barnes, 1972; Sahakian, Robbins, Morgan, \& Iversen, 1975; Valzelli, 1969), have larger adrenal glands (Geller, Yuwiler, \& Zolman, 1965; Hatch, Wiberg, Baloza, \& Grice, 1963), and generally do not perform as well in learning tasks (Bingham \& Griffiths, 1952; Morgan, 1973; Morgan, Einon, \& Nicholas, 1975).

Furthermore, rats raised in enriched environments are known to have greater central nervous system (CNS) cholinergic activity than isolated animals (Diamond, Rosenzweig, Bennett, Linder, \& Lyon, 1972), while individually housed rats have been shown to have a higher basal turnover rate or brain-

This work was partially supported by Grant 5T32MH14286-02 from the National Institutes of Health. The authors wish to thank Bruce Gelotte for his valuable assistance in conducting this experiment and Ms. Kenny McClain for preparing the manuscript. stem norepinephrine (Stolk, Conner, \& Barchas, 1974). Significant differences in whole-brain levels of norepinephrine and dopamine have not been found between isolated and socially reared rats (Sahakian et al., 1975). Welch and Welch (1971), however, have reported differences in the levels of several neurotransmitters following the differential rearing of mice.

Chronic exposure to overcrowded conditions has also been reported to produce a variety of behavioral àbnormalities (e.g., Goeckner, Greenough, \& Mead, 1973). Although little is known about the neurochemical mechanisms responsible for these changes, it has been suggested that differences in behavior induced by high population density in mice are associated with significant changes in catecholamine metabolism (Ng, Marsden, Colburn, \& Thoa, 1973). Thus, density may have an important influence on behavior and at least some neurochemicals.

This research investigated the long-term effect of social enrichment or isolation in rats on repeated testing of locomotor activity and on the subsequent response to cholinergic drugs. Locomotor activity was chosen as the behavioral measure since it has been found to consistently differentiate isolated and socially reared animals, and it is also a sensitive behavioral measure for drug assessment. It is not clear from the literature, however, what effect the experi- 
mental procedues of handling and injection of animals might have on the behavioral and physiological differences between isolated and socially raised animals. Most investigations comparing isolates and socially reared animals on activity have not used more than 2 or 3 successive test days (e.g., Einon, Morgan, \& Sahakian, 1975; Gardner, Boitano, Mancino, D’Amico, \& Gardner, 1975; Morgan \& Einon, 1976). If the main source for the isolation-induced abnormalities is tactile, then behavioral and physiological differences between isolated and socially reared animals might be reduced or eliminated by the daily tactile stimulation involved in handling the animals. Repeated testing of the same subject offers an excellent experimental control, especially in pharmacological research, if it can be shown that repeated testing does not significantly alter the basic behavior and physiology of the animals under study.

Thus, the first purpose of this study was to investigate whether the activity differences usually found between isolated and socially reared animals would be reduced with repeated daily testing over 16 days or if these differences were reliable and not easily disrupted.

Although evidence has accumulated that rats reared in a crowded environment are, like isolationreared rats, inferior to those raised in smaller social groups on learning tasks (Leicht, King, \& Harvey, Note 1), data comparing them on simple locomotor activity is lacking. Since stress has most often been proposed as a possible cause for the physiological changes seen following isolation, and experiments with rodents have indicated that a high population density also stresses the animal, a second purpose of this investigation was to examine whether rats reared in a high-density condition would be similar to either isolation-reared or socially reared (low-density) animals on a measure of activity.

Third, since a major neurochemical difference between enriched and isolated animals is cholinergic, we investigated the effects of two drugs known to modify CNS cholinergic activity, scopolamine hydrobromide and physostigmine sulfate. Scopolamine is an anticholinergic drug, which blocks transmission at cholinergic synapses. Physostigmine prevents acetylcholinesterase from hydrolyzing acetylcholine (ACh), thus facilitating the effects of $\mathrm{ACh}$ at the synapse. CNS neurochemical differences can be indirectly demonstrated by the differential effects of drugs on the behavior of animals. For example, Katz and Steinberg (1970) have reported altered response to morphine and Hughes and Syme (1972) have found a differential response to chlordiazepoxide on locomotor activity following the rearing of rats under different housing conditions. Sahakian et al. (1975) have recently found a differential response to several dopaminergic drugs.
If isolated and socially reared animals have different levels of cholinergic activity, possibly drugs which modify the cholinergic system would affect them differentially and these differences would be reflected in locomotor activity.

\section{METHOD}

\section{Subjects}

Thirty male Charles River Sprague-Dawley albino rats were obtained from Carworth Co. (Mass.) at 23 days of age and served as the subjects in this experiment. They were housed as described below and had ad-lib food and water available through the experiment.

\section{Rearing Conditions}

Upon arrival in the laboratory, the rats were unsystematically assigned to three groups of 10 animals each and housed in the appropriate condition.

In the isolated condition (Group I), each rat was housed individually in a single standard rat cage (Wahman, $7 \times 10 \times$ 7 in.). The front and bottom of the cages were wire mesh, and isolated rats could hear and smell other rats, but could not see them.

In the low-density condition (Group LD), the animals were reared together in a double standard rat cage (Wahman, $16 \times$ $10 \times 7$ in.) with wire-mesh front and bottom.

The high-density condition (Group HD) consisted of 10 rats reared together in a single standard rat cage of the same dimensions as those in Group I. When these rats were approximately $\mathbf{5 0}$ days of age, a wire-mesh top was fitted on the cage to ensure adequate ventilation.

The subjects remained in these housing conditions throughout the experiment, and none of the animals were handled until testing began at 75 days of age.

\section{Apparatus}

The apparatus consisted of two Lehigh Valley 24-in.-diam photoactivity chambers (Model \#145-03) in which the number of beam interruptions was recorded automatically.

\section{Procedures}

Each rat was placed singly in the activity chamber for daily 15-min test sessions. Beginning on the 6th day of testing, the subjects were weighed and given intraperitoneal (IP) injections of distilled water $(1 \mathrm{cc} / \mathrm{kg}) 30 \mathrm{~min}$ prior to the test session. This procedure was followed for the next 10 days in order to adapt the animals to the injection procedure. A trend analysis of these 10 days was not significantly, indicating that a stable baseline had been established.

In the second phase of the experiment, the effects of two drugs known to alter cholinergic activity, scopolamine hydrobromide (SCOP) and physostigmine sulfate (PS), were assessed. The drugs were obtained from the Sigma Chemical Co. and were mixed in distilled water such that the rat always received $1 \mathrm{cc} / \mathrm{kg}$ of solution. Each drug was administered for at least 2 consecutive days preceded by at least 3 days of water injections. The drug dosagts were administered in the following order: $1.0 \mathrm{mg} / \mathrm{kg}$ SCOP ( 3 days), $10.0 \mathrm{mg} / \mathrm{kg}$ SCOP (2 days), $0.1 \mathrm{mg} / \mathrm{kg}$ PS (2 days), and $0.05 \mathrm{mg} / \mathrm{kg}$ PS ( 2 days).

Seven additional days were allowed between the administration of SCOP and PS and between the two doses of PS. The days between each drug dose were used to recover baseline activity levels and to ensure that the drug had been completely eliminated from the system.

The baseline defined in Phase 1 was for purposes of evaluating the effects of prolonged handling and to demonstrate the presence of a stable baseline. The baselines for the drug studies were 
defined as the 3 days of vehicle injection preceding each drug dose. The baseline was reestablished between the two doses of SCOP; thus the effects of both doses were analyzed relative to the same baseline. The baseline between doses of PS was not reestablished, thus each dose of PS is analyzed relative to a different baseline.

\section{RESULTS}

\section{Body Weight}

The mean body weights for Groups I, LD, and $\mathrm{HD}$ at the start of testing (age 75 days) were 428 , 372 , and $304 \mathrm{~g}$, respectively. These differences were significant $(\mathrm{p}<.001)$ and confirm previous reports of weight differences following differential social rearing conditions (Morgan, 1973). The body weights on the last day of testing (age 122 days) were 552, 479 , and $385 \mathrm{~g}$ for the I, LD, and HD groups, respectively. These differences were also significant $(\mathrm{p}<.001)$.

\section{Baseline Activity}

The daily activity scores for the three groups are shown in Figure 1. It can be seen that activity levels tended to decrease on the first few days of testing before reaching a stable level. A trend analysis indicated that this decrease was significant $(\mathrm{p}<.001)$.

A repeated measures analysis of variance on the daily baseline activity levels also yielded a significant group effect $(p<.001)$. Individual comparisons using Duncan's multiple range test indicated that the activity of Group I was significantly higher than the HD $(p<.01)$ and LD $(p<.05)$ groups, which did not differ significantly from each other. Comparisons of the slopes of the baseline activity over the 16 days were not significantly different.

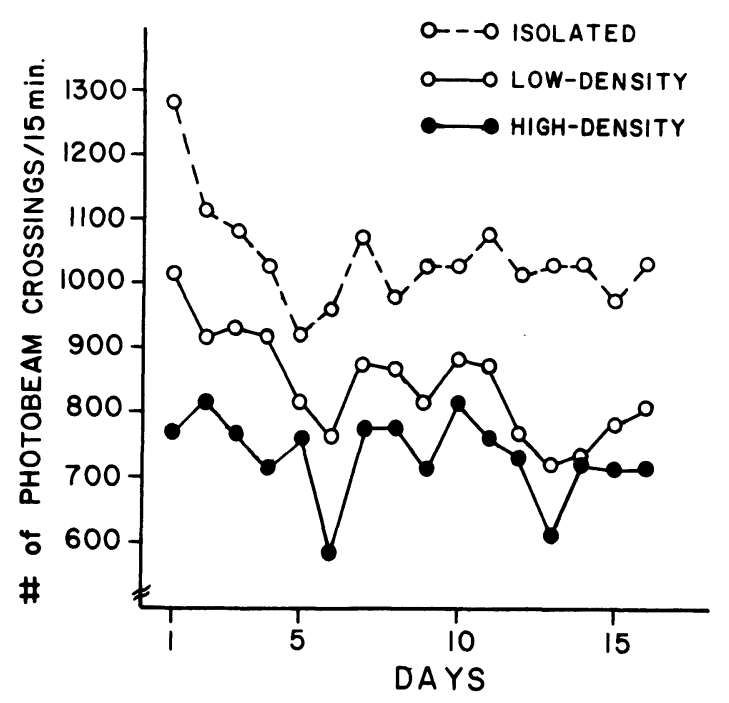

Figure 1. The mean daily locomotor activity of animals raised in isolated, low-density and high-density rearing conditions.

\section{Drug Effects}

Scopolamine. The mean number of photobeam crossings for all 6 of the control (vehicle injection) days was combined for each animal and was used as the baseline activity level. The number of photobeam crossings for each animal was averaged for the 3 days on each drug. The absolute and relative difference between baseline and drug scores for each animal was determined. The data were analyzed by performing a separate analysis of variance on each of these measures for each dose.

There was not a significant difference in absolute and relative change scores in activity for either the 1or the $10-\mathrm{mg} / \mathrm{kg}$ dose of SCOP. These results indicate that there was not a significant Drug by Housing interaction for scopolamine.

To determine if either dose of the drug altered activity, Duncan's multiple range test was computed for the absolute and relative change scores within each rearing condition. The $1.0-\mathrm{mg} / \mathrm{kg}$ dose of SCOP did not significantly alter the activity of any group. The $10.0-\mathrm{mg} / \mathrm{kg}$ dose significantly decreased the activity of Groups I and LD, but did not affect the HD social group.

Physostigmine. During the course of testing with PS, three animals died and were not included in the PS analyses. The data for the PS analyses are shown in Table 1 , as is the number of animals per group. The data were analyzed as described above for SCOP, with one exception. Since the baseline following the first administration of PS was not recovered, separate baselines were computed for each dose of PS. Thus, the baselines for the PS analysis consisted of the average of the 3 days before each dose and the average of the 2 days of drug administration for each dose.

There was not a significant difference in the effects of PS on either the absolute or relative change scores for either the .05- or the $.1-\mathrm{mg} / \mathrm{kg}$ doses of PS. These results indicate that there was not a significant Drug by Housing interaction for physostigmine.

Both doses of PS significantly decreased activity in Group I. Only the $.1-\mathrm{mg} / \mathrm{kg}$ dose decreased activity in Group LD, and neither dose significantly affected the behavior of Group HD.

\section{DISCUSSION}

These results confirm previous reports of high activity levels following isolation rearing in the rat (e.g., Levitsky \& Barnes, 1972; Sahakian et al., $1975)$ and provide important information regarding the stability of this difference and the possibility of obtaining a stable behavioral baseline for drug investigation. Although all groups decreased in activity over the first few days of testing, the heightened activity of isolation-reared animals is long-term and the difference between isolated and socially reared 
Table 1

The Effects of Scopolamine on Activity

\begin{tabular}{ccccccc}
\hline & & & \multicolumn{4}{c}{ Mean Change in N and Percent $\dagger \dagger$} \\
\cline { 4 - 6 } Group & $\mathrm{N}$ & Baseline $\dagger$ & \multicolumn{2}{c}{$1.0 \mathrm{mg} / \mathrm{kg}$} & \multicolumn{2}{c}{$10 \mathrm{mg} / \mathrm{kg}$} \\
\hline ISO & 10 & 1018 & -91.3 & $(-10)$ & -303 & $(-30)^{* * *}$ \\
LD & 10 & 782 & -105 & $(-12)$ & -186 & $(-23)^{* *}$ \\
HD & 10 & 717 & -1.6 & $(-2)$ & -128 & $(-15)$ \\
\hline
\end{tabular}

The Effects of Physostigmine on Activity

\begin{tabular}{|c|c|c|c|c|c|c|c|}
\hline \multirow{3}{*}{$\begin{array}{c}\text { Group } \\
\text { ISO } \\
\text { LD }\end{array}$} & \multirow{2}{*}{$\frac{N}{9}$} & \multirow{3}{*}{$\begin{array}{c}\text { Baseline 1 } \\
909\end{array}$} & \multicolumn{2}{|c|}{ PS $(.05 \mathrm{mg} / \mathrm{kg})$} & \multirow{2}{*}{ Baseline 2} & \multicolumn{2}{|c|}{ PS $(.1 \mathrm{mg} / \mathrm{kg})$} \\
\hline & & & \multicolumn{2}{|c|}{ Mean Change and Percent } & & \multicolumn{2}{|c|}{ Mean Change and Percent } \\
\hline & $\begin{array}{r}9 \\
8 \\
10\end{array}$ & & $\begin{array}{l}-149 \\
-94 \\
-81\end{array}$ & $\begin{array}{l}(-16)^{*} \\
(-10) \\
(-9)\end{array}$ & $\begin{array}{l}937 \\
807 \\
689\end{array}$ & $\begin{array}{l}-218 \\
-178 \\
-80\end{array}$ & $\begin{array}{l}(-24)^{* *} \\
(-21)^{*} \\
(-9)\end{array}$ \\
\hline
\end{tabular}

Note-Analyses of variance performed on absolute and relative change scores indicate that neither drug had a differential effect on the activity of animals housed in isolation or in groups. Decreases in activity were found following the administration of both drugs. ${ }^{*} p<.05 \quad$ tMean number of photobeam crossings per $15 \mathrm{~min}$.

${ }^{* *} p<.01 \quad$ ttMean change in number and percent of photobeam crossings from baseline.

animals does not diminish with repeated testing. The difference between the two socially reared groups, however, was not significant. It is clear from these data that repeated daily handling does not reduce the effects of isolation-rearing on activity and suggests that tactile stimulation alone cannot easily reverse this effect of isolation. Thus, stable behavioral baselines can be obtained in locomotor activity in differentially reared animals, and such baselines may be useful in pharmacological and physiological investigations.

The effects of handling may be more important in a comparison of low-density and high-density rearing. The difference in activity between these two groups on Day 1 was clearly larger than after handling and nearly nonexistent near the end of the baseline testing. The use of these two groups in a comparison of pharmacological effects would be limited.

High population density, like isolation, is often viewed as stressful. However, in this study the activity of the high-density or crowded rats was not at all similar to that of the isolates. Casual observation of the rats indicated that only the isolated rats appeared emotional upon the initial handling experience, but even this group became placid following repeated handling. Furthermore, activity levels after the first injection experience (Day 6) do not lend support to any groups being "hyperemotional" as a result of this presumably stressful experience. Thus, these results shed no light on the possible mechanisms responsible for the learning impairment usually reported following crowding distress in rats.

A decrease in activity following $10 \mathrm{mg} / \mathrm{kg}$ of scopolamine is consistent with the finding by Adams (1973) that wheel-running activity is decreased by low doses of scopolamine. Other studies, utilizing tiltcage and open-field measures of activity, however, have found that scopolamine is disinhibitory and that low doses of the drug increase activity (Campbell, Lytle, \& Fibiger, 1969; Hughes, Blampied, \& Stewart, 1977; Stewart \& Blain, 1977). We have compared (unpublished observations) wheel-running and activity in photo-cell chambers and found a high correlation between the two measures. This suggests that the disinhibitory effects of scopolamine on activity are greatly dependent on the type of apparatus used.

Although this is the most likely explanation for the difference observed among these studies, it has also been reported that the size and complexity of the environment affect base rate activity level and druginduced changes in activity (Stewart, 1975a, 1975b). The activity chambers in this experiment were quite large. Furthermore, the animals had been given extensive experience with them which may have been a factor. The time between injection and testing also may have been a variable, since Stewart and Blain (1977) found that the effects of scopolamine decreased over a 30-min session. Since $30 \mathrm{~min}$ elapsed between injection and testing in this experiment, these data may reflect time-related effects of scopolamine on activity.

Since we did not find a significant differential effect of either drug on animals raised in different density conditions, these data do not strongly support the hypothesis that cholinergic transmission is different in isolated and socially reared animals. There are several possible interpretations of this result. One possibility is that the behavioral measure used in this study was not sensitive enough to cholinergic modification, in which case differential 
drug effects might be more easily obtained employing other behaviors such as learning.

Secondly, it has been found that several of the complexity-isolation differences in cerebral weights and enzyme measures tend to be maximal within 15-20 days of differential rearing and diminish when differential rearing is continued beyond this time (Rosenzweig, Bennett, \& Diamond, 1967; Diamond et al., 1972). The animals in this study had been reared in their respective conditions for 53 days before the start of testing, which may have been too late to detect differences in their response to cholinergic drugs. It may also be that the subtle behavioral changes observed following repeated handling reflect altered neurochemistry which resulted in an attenuated differential response to the drugs.

An alternative explanation is that socialenrichment alone is not sufficient to modify cholinergic activity. Although numerous studies have shown altered brain changes following several types of social and perceptual enrichment, further experimentation may show that perceptual enrichment is the main source of increased cholinergic activity. This is consistent with the findings of Rosenzweig and Bennett (1972) who investigated the effects of perceptual enrichment on isolated animals and found that brain changes occur when animals are "primed" to interact with the environment, for example, following administration of amphetamines. The authors concluded that social contact may facilitate interaction with the environment but may not in itself produce many of the brain alterations known to occur following environmental enrichment.

In summary, these data suggest that isolation and high-density rearing both result in activity levels which are different from that produced by the more " "normal" circumstances of a moderate social environment. Most importantly, these differences are altered only slightly by daily handling over an extended period, indicating that baseline levels of activity can be established that may be useful in studying the underlying physiological mechanisms responsible for the changes seen following isolationrearing.

\section{REFERENCE NOTE}

1. Leicht, K. L., King, J. F., \& Harvey, M. J. Effects of population density and living space on learning performance. Paper presented at the Eastern Psychological Association Meeting, 1973, New York.

\section{REFERENCES}

Adams, P. M. The effects of cholinolytic drugs and cholinesterase blockade on deprivation based activity and appetitive behavior. Neuropharmacology, 1973, 12, 825-833.

Bingham, W. E., \& GRiffiths, W. J. The effect of different environments during infancy on adult behavior in the rat. Journal of Comparative and Physiological Psychology, 1952, 45, 307-312.
Campbell, B. A., Lytle, L., \& Fibiger, H. C. Ontogeny of adrenergic arousal and cholinergic inhibitory mechanisms in the rat. Science, 1969, 166, 635-637.

Diamond, M. C., Rosenzweig, M. R., Bennett, E. L., Linder, L., \& Lyon, L. Effects of environment enrichment and impoverishment on rat cerebral cortex. Journal of Neurobiology, 1972, 3, 47-64.

Einon, D., Morgan, M. J., \& Sahakian, B. J. The development of intersession habituation and emergence in socially reared and isolated rats. Developmental Psychobiology, 1975, 8, 553-559.

Gardner, E. B., Boitano, J. J., Mancino, N. S., D'Amico, D. P., \& GARDNER, E. L. Environmental enrichment and deprivation: Effects on learning, memory, and exploration. Physiology and Behavior, 1975, 14, 321-327.

Geller, E., Yuwiler, A., \& Zolman, J. F. Effects of environmental complexity on constituents of brain and liver. Journal of Neurochemistry, 1965, 12, 949-955.

Goeckner, D. J., Greenough, W. T., \& Mead, W. R. Deficits in learning tasks following chronic overcrowding in rats. Journal of Personality and Social Psychology, 1973, 28, 256-261.

Hatch, A., Wiberg, G. S., Baloza, T., \& Grice, H. D. Longterm isolation stress in rats. Science, 1963, 142, 507.

Hugres, R. N., \& Syme, L. A. The role of social isolation and sex in determining effects of chlordiazepoxide and methylphenidate on exploratory behavior. Psychopharmacologia (Berl.), 1972, 27, 359-366.

Hughes, R. N., Blampied, N. N., \& Stewart, W. J. Scopolamine-induced changes in activity and reactions to novelty. Pharmacology Biochemistry and Behavior, 1977, in press.

KATZ, D. M., \& STEINBERG, H. Long-term isolation in rats reduces morphine response. Nature (Lond.) 1970, 288, 469-471.

LEVItSKY, D., \& BARNes, R. H. Nutritional and environmental interactions in the behavioral development of the rat: Long-term effects. Science, 1972, 176, 68-71.

MoRGAN, M. J. Effects of post-weaning environment on learning in the rat. Animal Behaviour, 1976, 21, 429-442.

Morgan, M. J., \& Einon, D. F. Activity and exploration in thyroid-deficient and socially isolated rats. Physiology and Behavior, 1976, 16, 107-110.

Morgan, M. J., Einon, D. F., \& Nicholas, D. N. The effects of isolation rearing on behavioral inhibition in the rat. Quarterly Journal of Experimental Psychology, 1975, 27, 615-634.

Ng, L. K., Marsden, H. M., Colburn, R. W., \& Thoa, N. B. Population density and social pathology in mice. Differences in catecholamine metabolism associated with differences in behavior. Brain Research, 1973, 59, 232-330.

Rosenzweig, M. R., \& Bennett, E. L. Cerebral changes in rats exposed individually to an enriched environment. Journal of Comparative and Physiological Psychology, 1972, 80, 304-313.

Rosenzweig, M. R., Bennett, E. L., \& Diamond, M. C. Transitory components of cerebral changes induced by experience. Proceedings of the 75th Annual Convention of the American Psychological Association, 1967, 2, 105-106.

Sahakian, B. J., Robbins, T. W., Morgan, M. J., \& Iversen, S. D. The effects of psychomotor stimulants on stereotyping and locomotor activity in socially-deprived and control rats. Brain Research, 1975, 84, 195-205.

STEWART, W. J. Size of the environment as a determiner of effects of scopolamine. Psychological Reports, 1975, 37, 175-178. (a)

STEWART, W. J. Environment complexity does affect scopolamineinduced changes in activity. Neuroscience Letters, 1975, 1 , 121-125. (b)

Stew ART, W. J., \& Blain, S. Dose response effects of scopolamine on activity in an open field. Psychopharmacologia (Berl.), 1977, in press.

Stolk, J. M., Conner, R. L., \& Barchas, J. D. Social environment and brain biogenic amine metabolism in rats. Journal of Comparative and Physiological Psychology, 1974, 87, 203-207. 
Valzelli, L. Aggressive behavior induced by isolation. In S. Garattini \& E. G. Sigg (Eds.), Aggressive behavior. New York: Wiley, 1969. Pp. 70-76.

WeLCH, A. S., \& WeLCH, B. L. Isolation, reactivity, and aggression: Evidence for an involvement of brain catecholamines and serotonin. In B. B. Eleftheriou \& J. P. Scott (Eds.), The physiology of aggression and defeat. New York: Plenum Press, 1971. Pp. 91-142.

(Received for publication May 24, 1977; revision accepted October 14, 1977.) 